\title{
A Parabolic Trough Baking Device Developed in Lesotho
}

\author{
Ivan Yaholnitsky \\ Bethel Business and Community Development Centre, Lesotho.
}

\begin{abstract}
How to cite this paper: Ivan Yaholnitsky. (2020) A Parabolic Trough Baking Device Developed in Lesotho. International Journal of the Science of Food and Agriculture, 4(4), 354-366.

DOI: $10.26855 /$ ijfsa.2020.12.001
\end{abstract}

Received: August 31, 2020

Accepted: September 28, 2020

Published: October 13, 2020

*Corresponding author: Ivan Yaholnitsky, Bethel Business and Community Development Centre, Lesotho.

Email: ivan.yaholnitsky@gmail.com

\begin{abstract}
This paper describes technical, operational and financial metrics related to a parabolic trough solar cooking device first developed by the author in 2004 in Lesotho. It is a baking tube with a diameter of $200 \mathrm{~mm}$ which lies in the focus of the parabolic trough and has an overall 10:1 concentration ratio. The device has been in continuous use since then, along with other ovens of the same type, primarily used for baking in the framework of a small cottage bread baking application. The paper describes the physical characteristics of the solar oven and its operating context. The materials and precise geometry employed is examined, along with innovations applied over the course of many years of development. As well, shop procedures for manufacture are described along with operating experience, in terms of doing applied commercial work in an authentic setting. The conclusion summarizes financial indicators, costs and potential revenues, return on investment, and prospective for scaling, extension and replication, along with contemporary linkages to the Sustainable Development Goals and energy parameters in Lesotho.
\end{abstract}

\section{Keywords}

Solar Cooking, Parabola, Bakery, Innovation, Manufacture, SDG’s

\section{Introduction}

Solar cooking is an attractive proposition in Lesotho because of excellent atmospheric conditions. As well, the country has no fossil fuel resources and biomass is scarce. Solar energy is abundant, free and literally on everyone's doorstep. This paper provides an overview of a concentrating device that is robust, obtains high temperatures, and proven over many years of use, application and development. The parabolic trough described has a simple two axis tracking system that is manually operated, and which enables the device to operate for several hours each day.

\section{Materials and Methods}

\subsection{Technical Specifications}

The dimensions of the parabola in mm are given by the formula: $y=x^{2} / 1,500$

This gives a centre of focus at $375 \mathrm{~mm}$ from the central axis. This solution was arrived at by comparing potential solar capture with different parabolic geometries. It was chosen because it combined sufficient solar capture with a focal position near enough to the trough to minimize optic distortion and advective losses. The absorber is quite large (200mm), which means that some distortion in the reflecting surface can be tolerated without too much loss of reflective radiation. I met Michel Grupp at the world conference on solar cooking in Kimberley, RSA in 2001 and explained to him what I wanted to do. He suggested that the focus be kept near to the central axis, while ensuring that the mouth of the trough was wide enough to obtain enough energy. Following a few sketches and number plots on graph paper with different parabolic functions, $y=x^{2} / 1,500$ (in mm) was settled on because it provided a 10:1 concentration ratio, and a 200mm 
diameter baking tube which is the necessary dimension for standard full size loaves of bread. A survey of the literature suggested that a $10: 1$ concentration ratio would provide the desired temperature range which is $200{ }^{\circ} \mathrm{C}$ [1]. Anodized aluminium sourced from Alanod in Germany was used for the reflector. The straight distance across the end of the trough is $2,400 \mathrm{~mm}$ and the distance along the curved edge is $3,200 \mathrm{~mm}$ from end to end. With a width of $1,250 \mathrm{~mm}$, this means that $4 \mathrm{~m}^{2}$ of the anodized aluminium is required. Its cost is $\mathrm{R} 300.00 / \mathrm{m}^{2}$. The effective solar aperture is $3 \mathrm{~m}^{2}$ or approximately 3,000 watts under full sun. The absorber employs Mirotherm, $(0.4 \mathrm{~mm}$ in thickness) which is a spectrally selective material with excellent absorbent properties. The absorber tube is $200 \mathrm{~mm}$ in diameter and $1,200 \mathrm{~mm}$ in length. Therefore, the rolled surface of the Mirotherm is approximately $0.75 \mathrm{~m}^{2}$ at a cost of $\mathrm{R} 500.00 / \mathrm{m}^{2}$. The optical values of the Mirotherm as provided by the manufacturer are:

Solar absorption: ásol $=0.94+0.02$

Thermal emission: $\varepsilon 100^{\circ} \mathrm{C}=0.05+0.02$

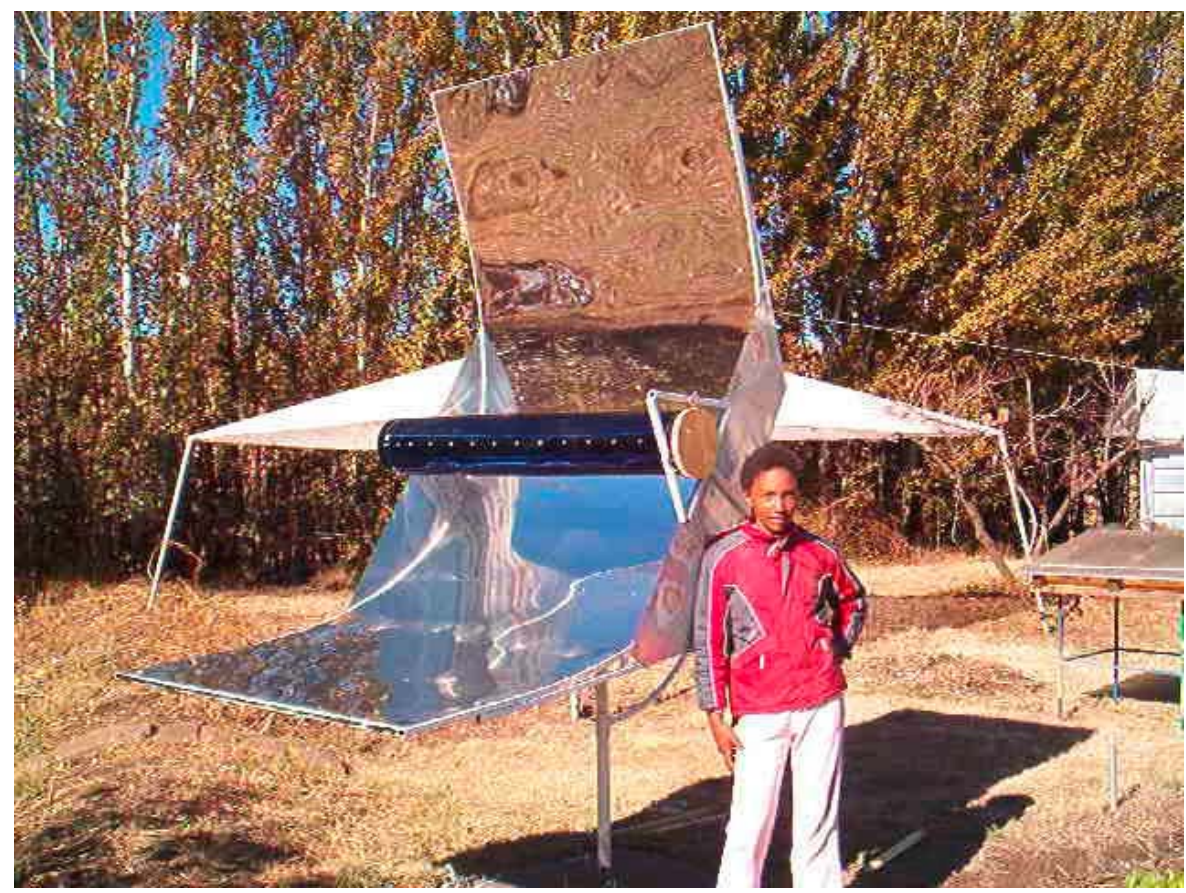

Figure 1. Front view of concentrator type baking device with the author's daughter Thung-Thung in the foreground. The absorber tube is loaded/unloaded by removing a plywood plug on the end of the tube. Pans are pulled out with a bamboo handle with a hook on the end.

The device illustrated in Figure 1 has operated continuously since June 2005. It is located in the author's front garden, and is about 10 paces from the kitchen door. The receiver tube is exactly $200 \mathrm{~mm}$ in diameter, and holds 4 large bread pans, or 5 smaller ones, or any combination of pans not longer than 1,200mm altogether. Under clear sunshine, the device performs well, and reaches good baking temperatures $\left(150-190^{\circ} \mathrm{C}\right)$ for up to 7 hours per day (9:00-16:00), and can be used even later in summer. It has a concentration ratio of approximately 10:1. Cool windy weather hampers operation of the device significantly, as advective cooling reaches a point where internal temperature in the baking tube drops below tolerable limits. In Lesotho, however, these instances are infrequent. Also, the garden where they are located is comparatively well sheltered by trees and a courtyard. In 2008, a second parabola identical to the first was added.

The advantages of the device are low cost, simplicity of fabrication, and ease of operation [2]. The drawbacks are that some of the materials may be difficult to source. Nevertheless, Bethel is remote and not well served by transportation or communications facilities. We were able to track down the special inputs required and obtain them for a reasonable price. Presently this device is being used by the author's wife to operate a bread baking cottage enterprise. There are only 3 pivot points, as illustrated in Figure 2. Neither of the pivot points requires precision engineering. The horizontal rotation "T" is a pipe in pipe swivel with a collar tack welded on, and the 2 vertical pivot points are just bolts with flat washers. While the oven must be manually actuated and adjusted (every 15 minutes), no mechanical or power driven devices are installed, which lowers the development costs and reduces maintenance problems. A small circular section of metal is allowed to protrude on one side of the trough. Aiming of the device is by means of checking on the shadow cast from the focuspoint on the ground (through the circular metal section) or on the circular metal section itself. Once the operator is accustomed to the fact that the shadow moves down in the morning and up in the afternoon (after the apparent altitude of the sun), it is relatively easy to keep the device focused and slightly ahead of the sun's position. 
Tracking on both elevation and azimuth axis allows the device to operate through most of the day. The three pivot points are clearly illustrated in Figure 2.

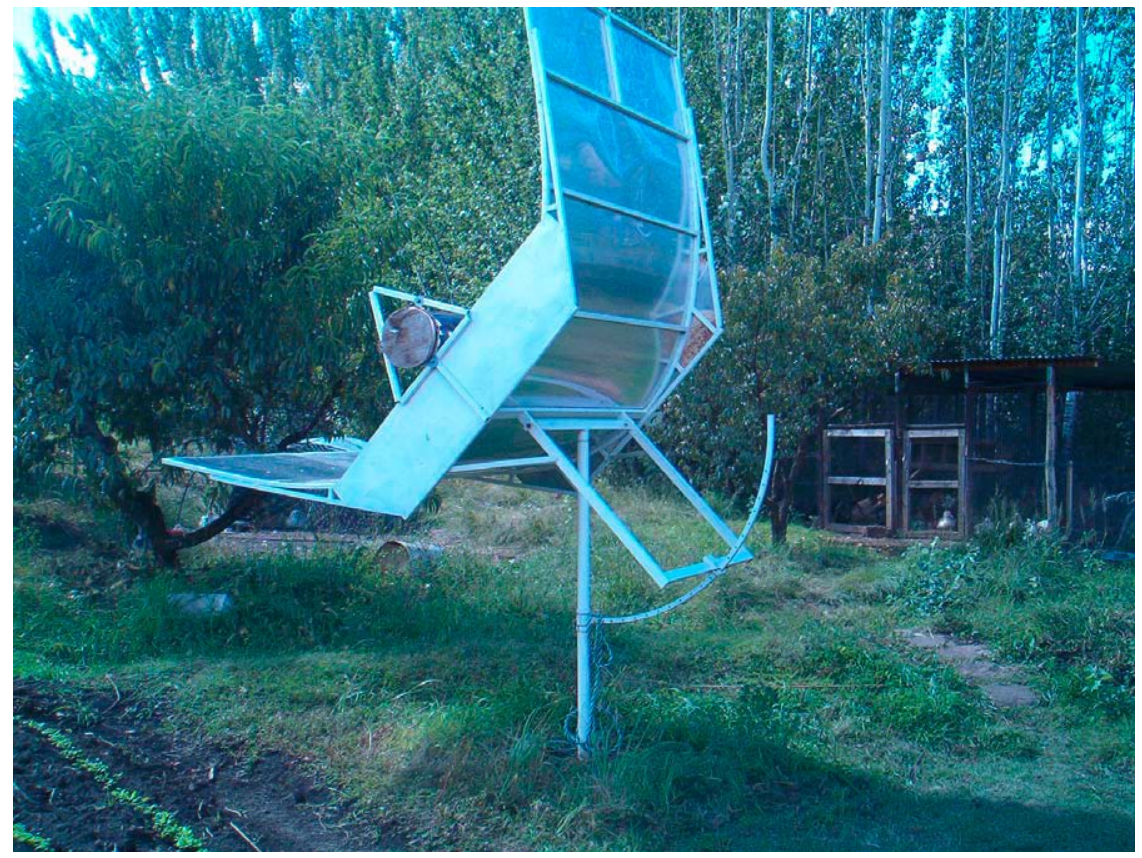

Figure 2. View of device from rear, and illustrating dual axis tracking and adjustment. Centre rotates for azimuth and pivots up or down for elevation.

\subsection{Operation, Experience and Performance}

The parabolic trough can bake bread in 40-60 minutes (1,000g loaf), depending on conditions, and muffins, cookies and small buns in 20 minutes. Finding the right cooking utensils is as important as anything else. Fortunately, we were able to find bread pans that measure $330 \mathrm{~mm}$ x $130 \mathrm{~mm}$ x $70 \mathrm{~mm}$ and half doz. muffin pans (see Figure 3) that fit perfectly in the tube and provide excellent heat transfer. I also made a long pan especially for it out of copper sheet and with soldered corner joints (see Figure 5). The high heat obtained is noticeable in Figure 4. Figures 6, 7, 8, 9 illustrate a range of baked goods possible with the device and solar power.

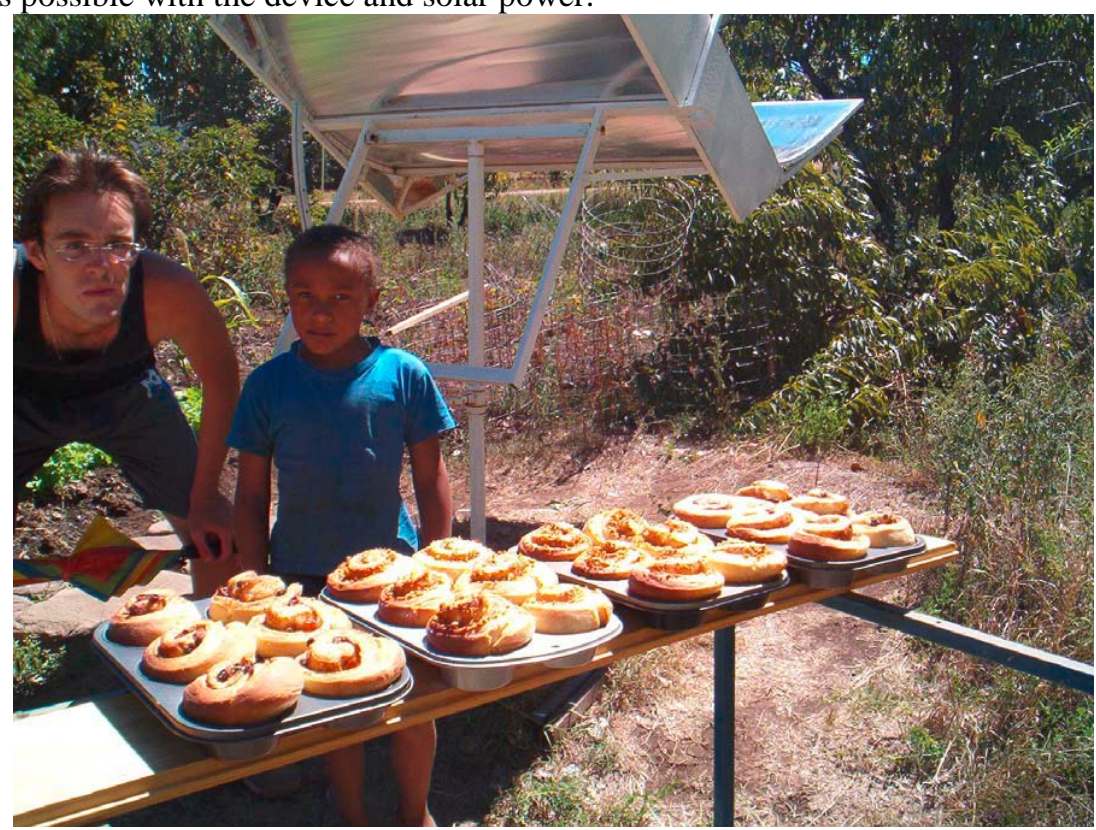

Figure 3. Cinnamon Buns baked in 20 minutes. Peace Corp Volunteer Timothy O'Connell and researcher's son John in background. 


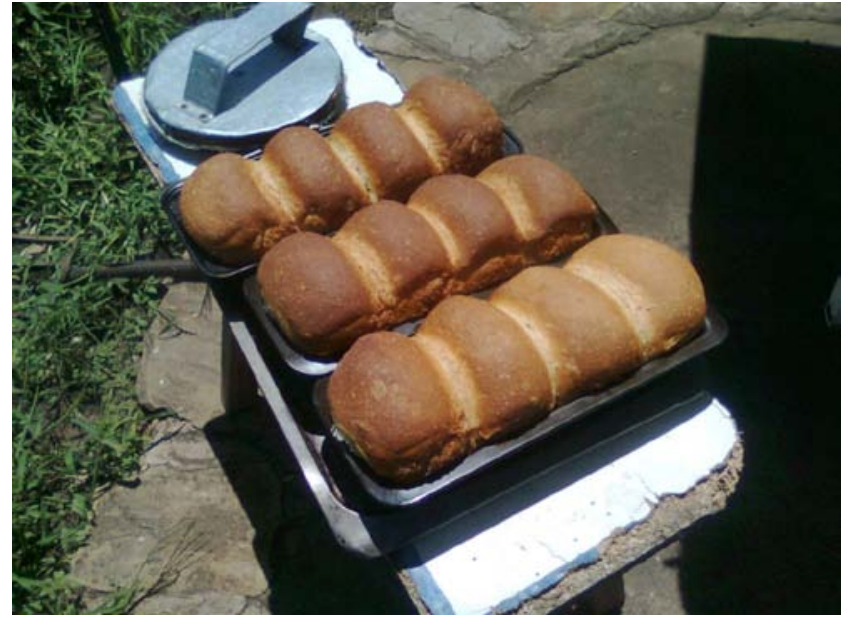

Figure 4. Bread.

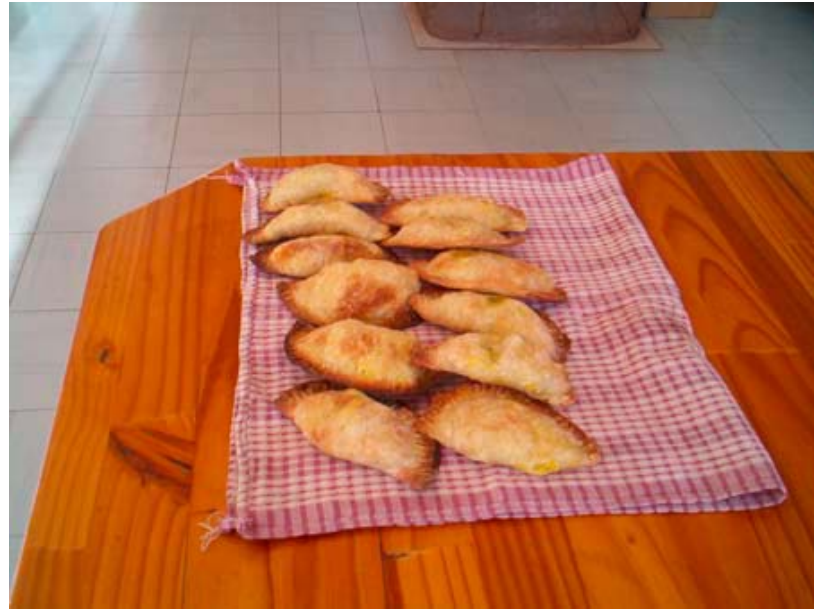

Figure 6. Turnovers

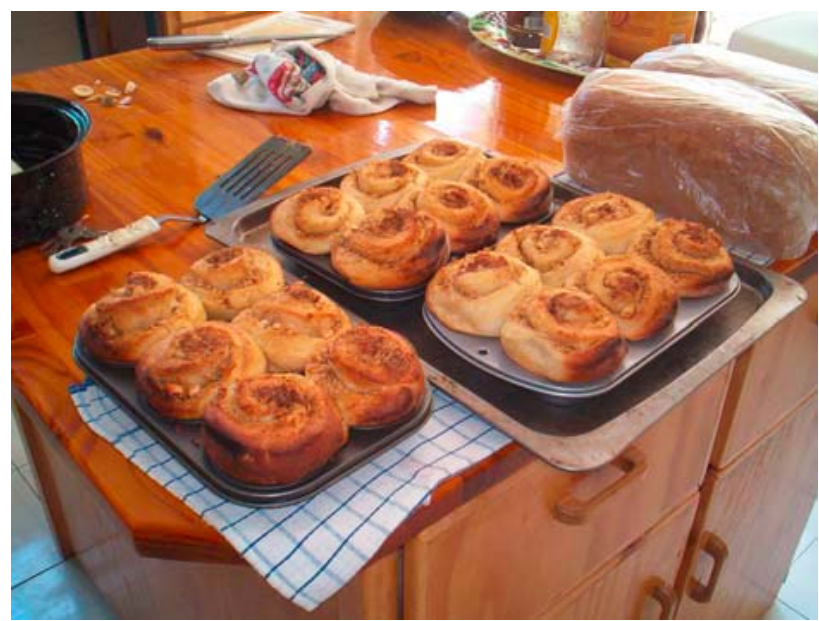

Figure 8. Coffee/almond/coconut rolls.

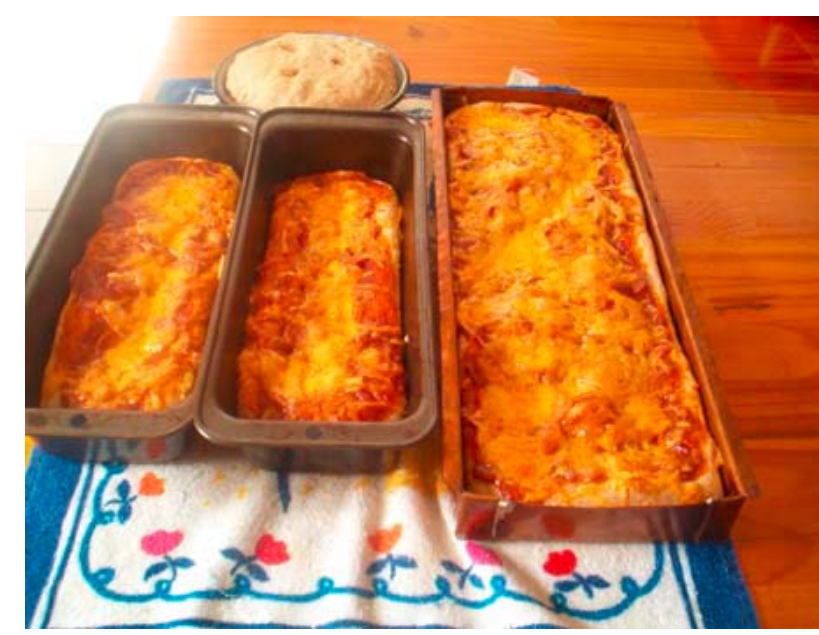

Figure 5. Pizza.

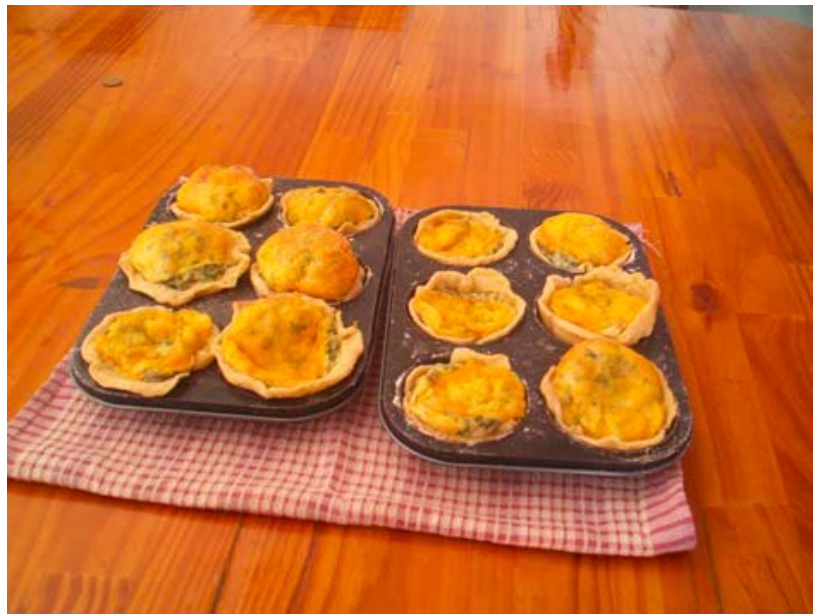

Figure 7. Tarts.

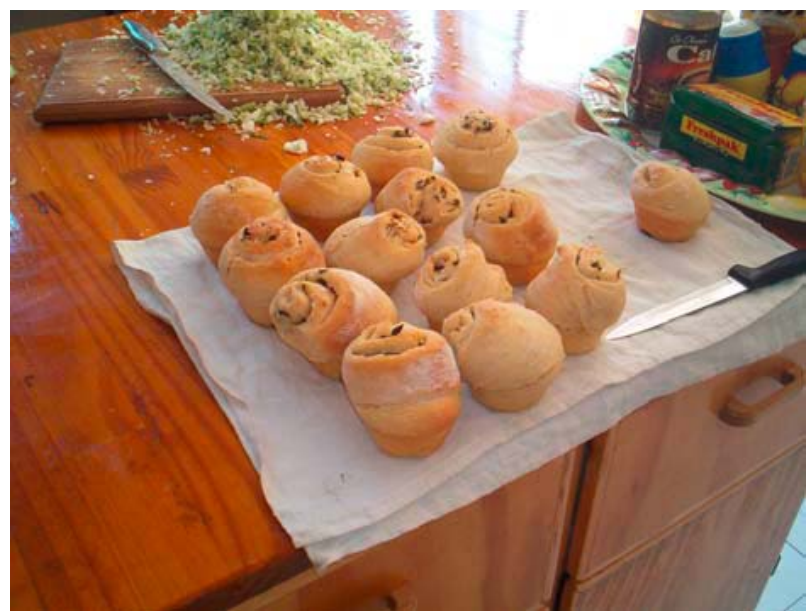

Figure 9. Herb rolls with sun dried tomato.

\subsection{Fabrication}

A template was made for the fabrication of the parabolic sections from a piece of plywood. Points were plotted using a T-square, and then the shape was carefully cut and sanded smooth. See Figure 10 for a refined template used to obtain the precise curvature. The parabolic end profile was shaped by making interval cuts with a hack saw $3 / 4$ of the way through $20 \mathrm{~mm}$ x $20 \mathrm{~mm} \times 1.6 \mathrm{~mm}$ square tubing. The current local price for this material is R16.00/m. The trough de- 
picted in Figure 2 used 24.0m of this material, for an approximate total cost of R384.00. These cuts were made symmetrically from the centre so that the tube would easily bend to close the gap of the cut and wrap to the shape of the parabolic template cut from plywood. The plywood was clamped to a large steel welding table with a flat surface and true $90^{\circ}$ corners. Straight sections of $20 \mathrm{~mm}$ square tubing were then added behind the curved section and braced with small truss pieces. This is apparent from Figure 10. Once the parabolic section was true and the truss sections securely clamped, these sections were welded using mild steel electrodes. The cuts made to achieve the curved shape were closed with rapid touch welds. Once the two end sections with a parabolic shape were completed, the device was set up and levelled carefully on a plane surface, and the lateral sections across the mouth of the trough were welded in place. More lateral sections would reduce sag and distortion of the reflective material, but increase cost and weight of the device. As well, perfect optics may actually put more stress on the absorber than it can endure. The anodized aluminium was pop-riveted to the square tubing using $4 \mathrm{~mm}$ pop rivets, spaced $200 \mathrm{~mm}$ on centre. The baking tube was made by rolling a sheet of Mirotherm, and pop riveting it to a rectangular steel frame welded from $20 \mathrm{~mm}$ x $20 \mathrm{~mm}$ square tubing. Prior to installation of the Mirotherm sheet, the inside surface which "sees" the bread was painted with black high heat paint. This is important because the $\varepsilon$ of shiny aluminium is extremely low, and undesirable. By painting the inside surface black, heat transfer by radiation is brought closer to its maximum potential. The loading end was kept unobstructed by rolling a $200 \mathrm{~mm}$ steel ring out of $20 \mathrm{~mm} \times 5 \mathrm{~mm}$ flat bar. Two pieces of $6 \mathrm{~mm}$ round bars were tack welded to the outside of the steel ring on the loading end to form a groove. This enables the baking tube to rotate and level. A pipe rotates in a collar at the opposite end of the baking tube.

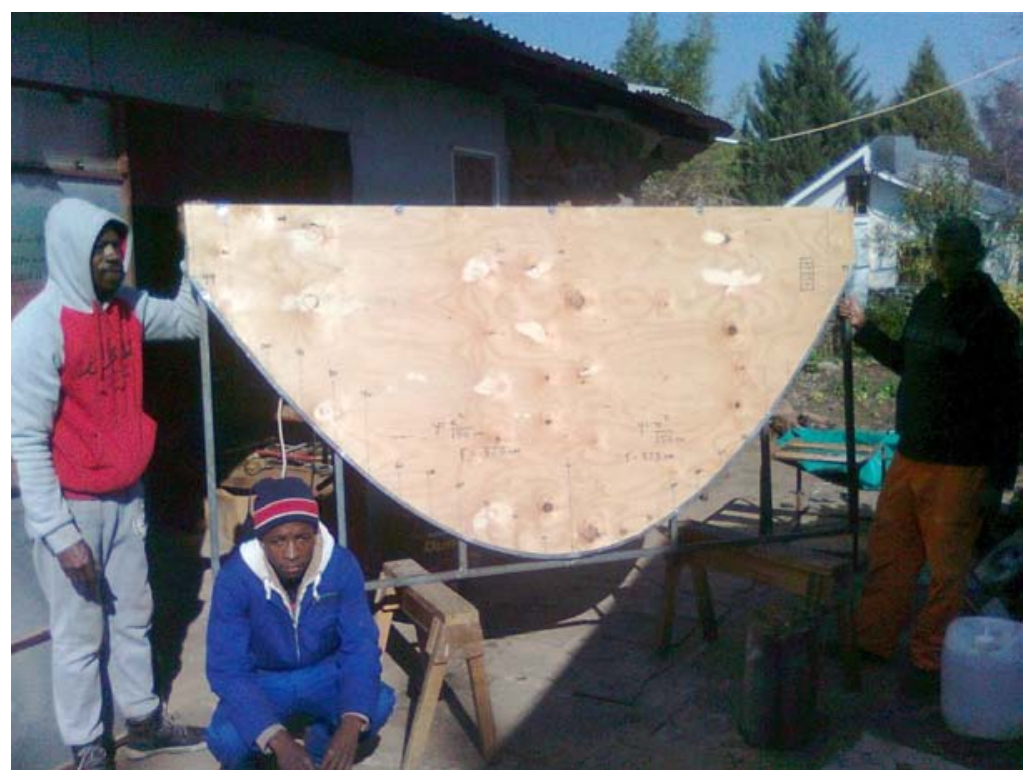

Figure 10. Template for welding the parabolic side sections.

\subsection{Economics and Financial Analysis}

Table 1 provides a summary of the main material costs for the parabolic oven.

Table 1. Summary of material costs for the device. R3659.00 (\$296.40 USD).

\begin{tabular}{ccc}
\hline Material & Description & Cost Per Unit \\
\hline Square tubing & 20mm x $20 \mathrm{~mm} \mathrm{x} 1.6 \mathrm{~mm}: 24.0 \mathrm{~m} \mathrm{R} 16.00 / \mathrm{m} 384.00$ \\
Anodized Aluminium & $3.0 \mathrm{~m}^{2} \mathrm{R} 300.00 / \mathrm{m}^{2}$ & $\mathrm{R} 900.00$ \\
Mirotherm & $0.75 \mathrm{~m}^{2} \mathrm{R} 500.00 / \mathrm{m}^{2}$ & $\mathrm{R} 375.00$ \\
Pipe and other steel & $\mathrm{R} 300.00$ \\
Welding (Estimate) & $\mathrm{R} 1,000.00$ \\
Fastening & $\mathrm{R} 300.00$ \\
Concrete Footing & $\mathrm{R} 300.00$ \\
Paint/Finishing & $\mathrm{R} 100.00$ \\
Total & $\mathbf{R ~ 3 , 6 5 9 . 0 0}$
\end{tabular}

$\$ 1.00$ USD $=$ R12.35 SA RAND (4/1/2018) 
Bread making is hard work. In the beginning, dough was mixed by hand, but soon after, a small industrial dough mixer was acquired. This eliminated much of the drudgery of the operation. Typically enough dough for 25-50 loaves is mixed each day. Loaves are sold for R9.00 each [3].

Thus far, there is no problem selling the output. The gross profit margin is about $60 \%$, providing a return to labour of approximately R200.00/day (more than double the local statutory minimum wage). For Lesotho, this is certainly a worthwhile undertaking for the entrepreneur, not to mention a high quality product for the local community. Each loaf of unbaked dough is weighed on an electronic kitchen scale to ensure a consistent product. The cost of the materials for the parabolic trough was approximately R3500.00. The researcher welded it together in spare time. Therefore, a realistic price for the device is estimated to be R6000.00. It is interesting to note that a solar powered mini-grid provided all the power for welding and finishing. What counts ultimately, is the payback period and the amount of cycling and duty that the machine can sustain each day and for how long. Mechanization of the dough mixing would certainly enable more baking each day. Special orders for more bread are often received due to local functions, and there is also a steady demand for specialty items like pizza, muffins, cookies, biscuits and cakes, which command a higher margin. Readers can draw their own conclusions, but pay back is quite rapid. It should also be mentioned that Bethel is a small remote community. A device like this located near dense urban clusters or transportation hubs will find a ready and strong market for baked goods. One advantage of a cottage enterprise is that on the chance that clouds suddenly appear and bread flops, it can still be consumed in the entrepreneur's own home. Occasional back up capacity is provided by a self-built energy efficient gas oven. This minimizes waste. As well, the device is frequently used to prepare other items for the domestic menu. In summer, this keeps a lot of unwanted heat out of the kitchen.

There is no local competition. Bread is trucked in from Maseru, and sells locally for R10.00 for $<600 \mathrm{~g}$ loaf. It is not fresh. The SA price for bread is R9.38 for 500g loaf. Therefore the locally produced product at Bethel is fully competitive, at R9.00 for a $1000 \mathrm{~g}$ loaf. The bread frequently sells as fast as it is pulled from the oven. Since the bakery started in 2005, the price of flour has not changed much, and reflects cost deflation, because it ranges between R300-R350.00/50kg bag.

\subsection{Innovation}

As with any technology, unanticipated problems emerge through operation. At $0.4 \mathrm{~mm}$ the Mirotherm is a thin and light material which is advantageous. Operationally, however, it became subject to excessive thermal stress and also abrasion on the bottom section where the pans of bread were sliding in and out on it several times per day. Abrasion wore the material through where the bread pans were inserted and removed and the efficiency of air tightness began to deteriorate after a couple of years of use. As well, continued thermal stress on the material resulted in creases and deformation which after many cycles resulted in tearing and rupture of the Mirotherm. These inadequacies and loss of thermal efficiency due to perforation called for a rethink of how the baking tube could be assembled and configured to overcome the thermal deformation and abrasion damage [4].

In 2014, it was decided to refurbish the baking tube and make it more robust. An inner liner of $0.9 \mathrm{~mm}$ aluminium sheet was added and new Mirotherm wrapped tightly and riveted on the outside. It was not clear whether the efficiency gain of greater air tightness would be offset by a loss of thermal heat transfer efficiency by conduction through the two layers. During assembly care was taken to spray paint the inner surface of the Mirotherm with high heat black spray paint, and both sides of the inner $0.9 \mathrm{~mm}$ sheet. This was done to optimize radiative transfer of heat between the two layers and also into the baking tube itself. Care was taken so that sealed edges were practically air tight along with the cap at the end of the baking tube. Overall thermal efficiency increased as a result of doubling the baking tube wall structure. Good heat transfer was maintained to the baking chamber, and the improved air tightness of the assembly resulted in higher baking temperatures which results in faster cycling times. The problem of abrasion on the bottom of the baking tube was overcome, as the thicker material at $0.9 \mathrm{~mm}$ is more robust. An unforeseen benefit is that the Mirotherm is now thermally more stable due to heat transfer to the inner liner and does not deform or crease as it did alone. At the same time, the door plug used to close the tube for baking was improved with a heat resistant seal and reflective face on the inside. Taken together, the above significantly improved the operational effectiveness of the device.

As everyone knows, wireless communications have swept around the world, including Lesotho. Access to data and information via smartphone technology is one of the wonders of the modern world. This development also impacts positively on a device and operation as described in this paper. Accurate daily and weekly weather forecasts enable rational planning and utilization of the technology. Lesotho experiences exceptionally benign streaks of solar cooking conditions. Figure 22 below illustrates a typical weekly weather forecast. With this in mind, the operator can predict and prepare with confidence for use of the device. BBCDC often receives scheduled visits and study tours, and accurate information on weather conditions enables effective scheduling of solar baking demonstrations. For several years, the bakery operated out of the home kitchen. The business outgrew the facilities and in January, 2013 construction of a small bakery building $\left(24 \mathrm{~m}^{2}\right)$ started on the east side of the residential house. Six months later, it was completed, and now houses the mixer, a back-up gas fired bake oven, sinks and hot water supply for washing up, and storage and work 
space. The bakery has good proximity to the parabolas which are just out in front.

The parabola is one part of a complex system of environmental and economic condition. Another innovation related to the operation of the parabolas is electrical power supply for dough mixing. In 2016, the author completed a small residential structure next to the bakery with a rotating roof for augmented power supply (Figure 23). As dough mixing must be done early in the morning, in a conventional off-grid power system this puts enormous strain on the batteries at a time of day when they are most vulnerable to long term degradation. As well, seasonal solar geometry means that a fixed north facing solar array receives little radiation in the morning during summer. The rotating roof is an attempt to overcome this problem, and achieve peak power almost immediately after sunrise. While tracking and operating systems for the rotating roof are still under development, the concept is sound. For at least 6 months of the year, the rotating roof can provide early morning power for the dough mixing operation and also other times of the day. This relieves fuel costs and dependence on a small petrol driven generator along with the noise and inconvenience and expense of buying fuel.

Another refinement of the parabolic baking system concerns manufacturing techniques and tooling for their production. Initial models were built using a one sided template that provided the shape for doing half the parabola at a time. While it worked, the procedure was somewhat cumbersome. During welding and fabrication one side was completed and then another. In 2016, a new template was built with an added light metal frame of steel angle iron. This template was built using $18 \mathrm{~mm}$ plywood and includes both left and right hand sides of the parabolic profile. The new assembly certainly streamlines and accelerates the speed and accuracy of manufacturing. The plywood template was also lined with sheet metal to protect the wood from welding heat and spatter. The original template was soon charred and damaged by heat from welding operations and the evolved unit is much sturdier and easier to use. Figure 11 shows the welding set up used with the template to construct accurate parabolic profiles. The completed frame is depicted in Figure 12; it is light weight and sturdy. The inner frame work for the baking tube is shown in Figure 13. The ring on the end is the door side which is fabricated in the shop by rolling a $5 \mathrm{~mm} \times 20 \mathrm{~mm}$ section of flat bar to make a perfect circle. Figure 14 demonstrates rolling of the Mirotherm for the baking tube and tensioning with a ratchet strap. A sheet metal rolling machine will expedite the procedure if it is available. Figures 15, 16, 17 make evident the final result and potential.

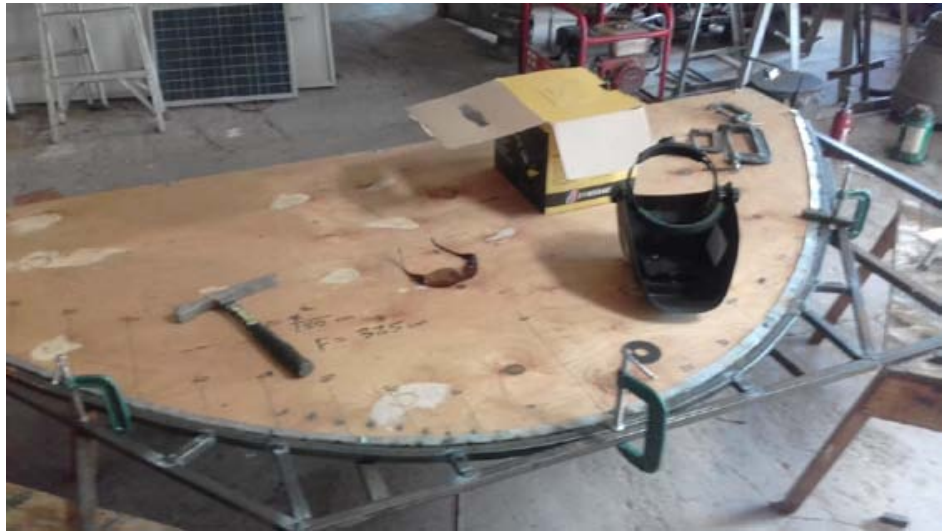

Figure 11. Template in use in shop with sections fitted and clamped for welding.

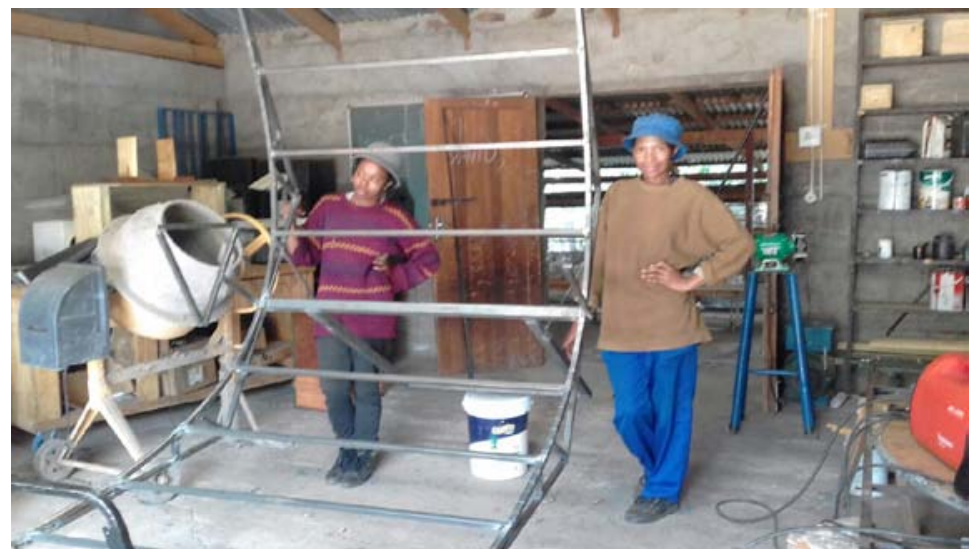

Figure 12. Completed parabolic frame ready for painting. 


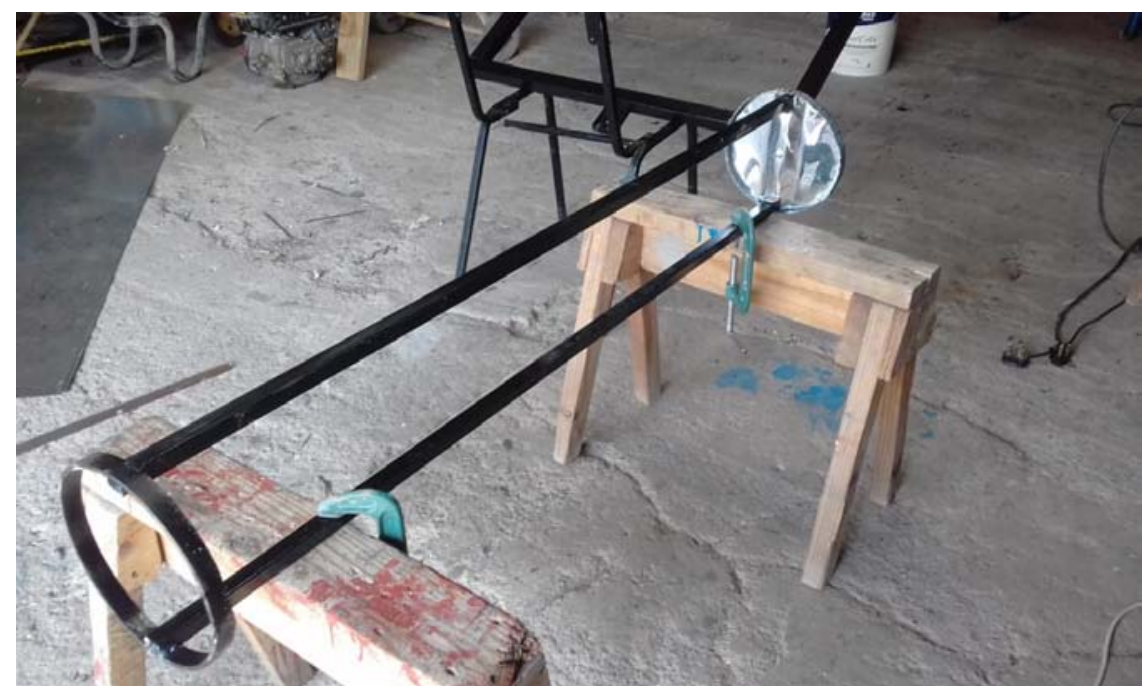

Figure 13. Structural ribs for baking tube.

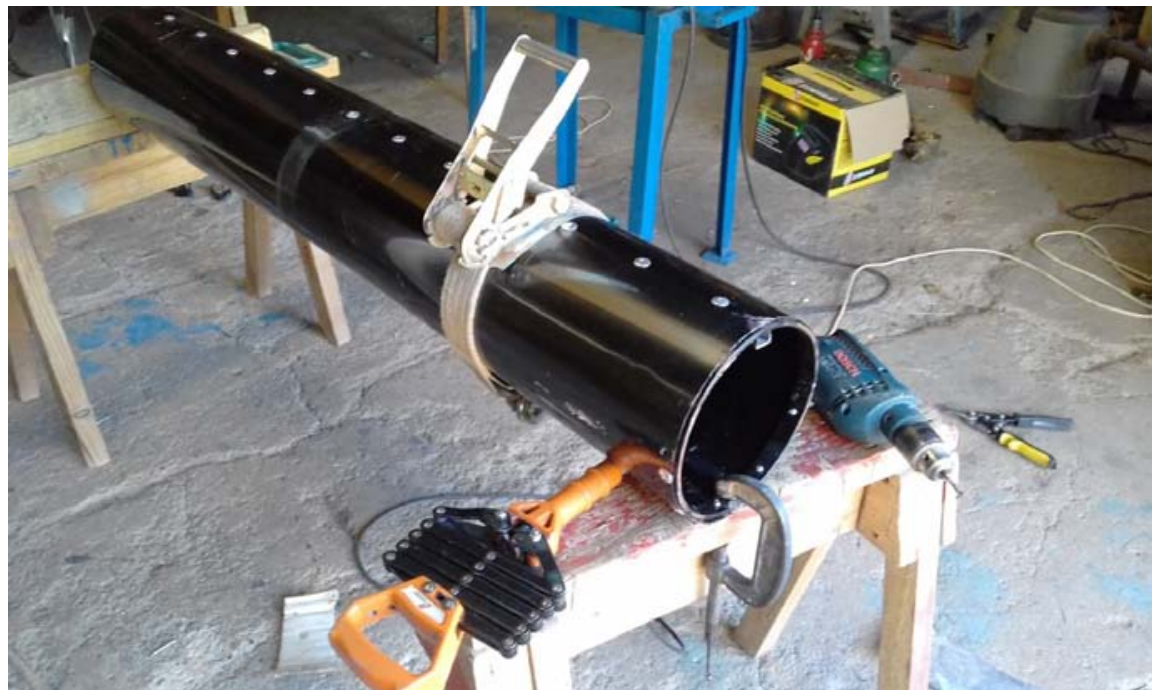

Figure 14. Covering of baking tube. Note that this tube is a double wall configuration with an inner sleeve of $0.9 \mathrm{~mm}$ aluminium sheet with a covering of Mirotherm with a selective coating at $0.4 \mathrm{~mm}$.

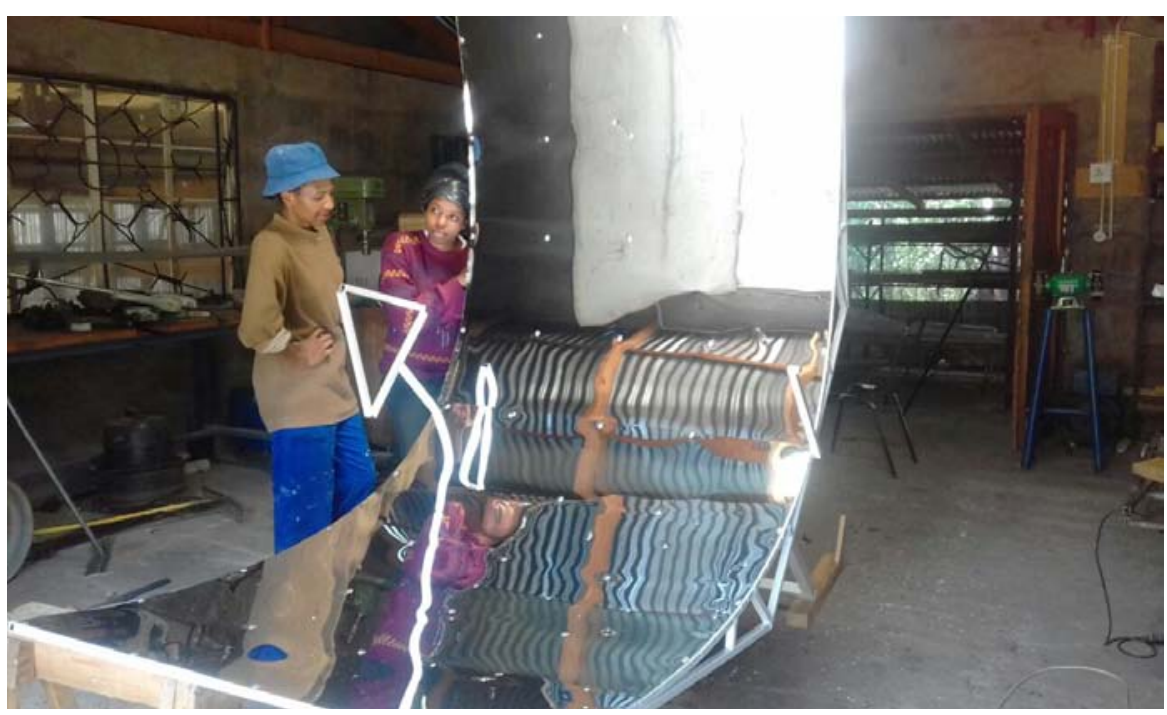

Figure 15. Reflective surface installed on light square tube frame. 


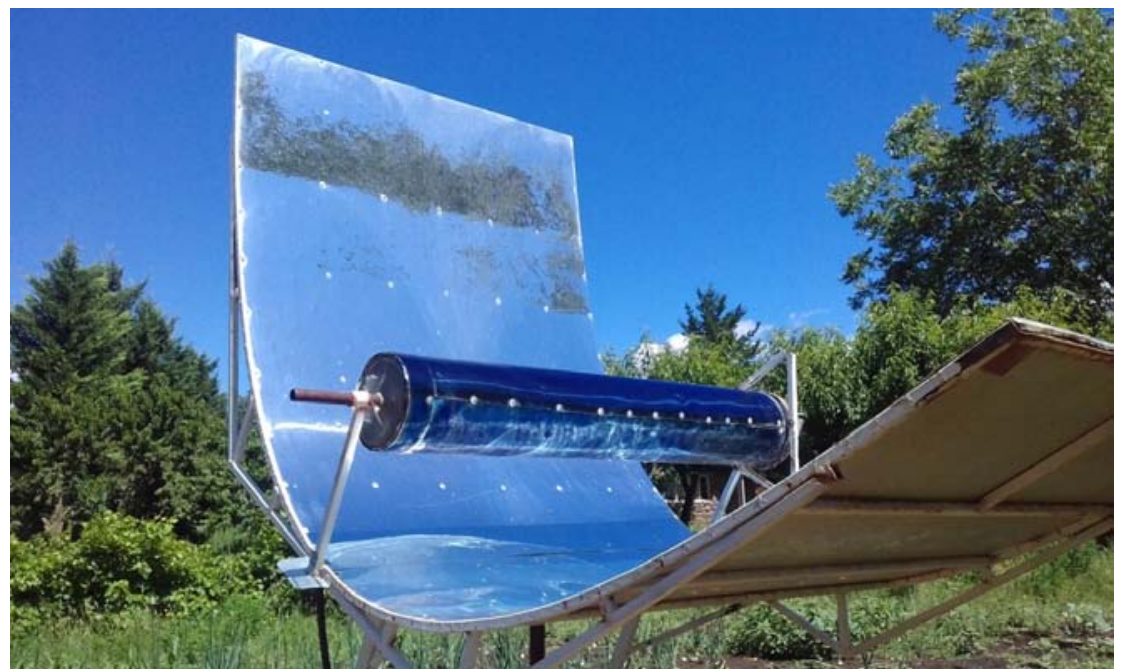

Figure 16. Baking oven in operation.

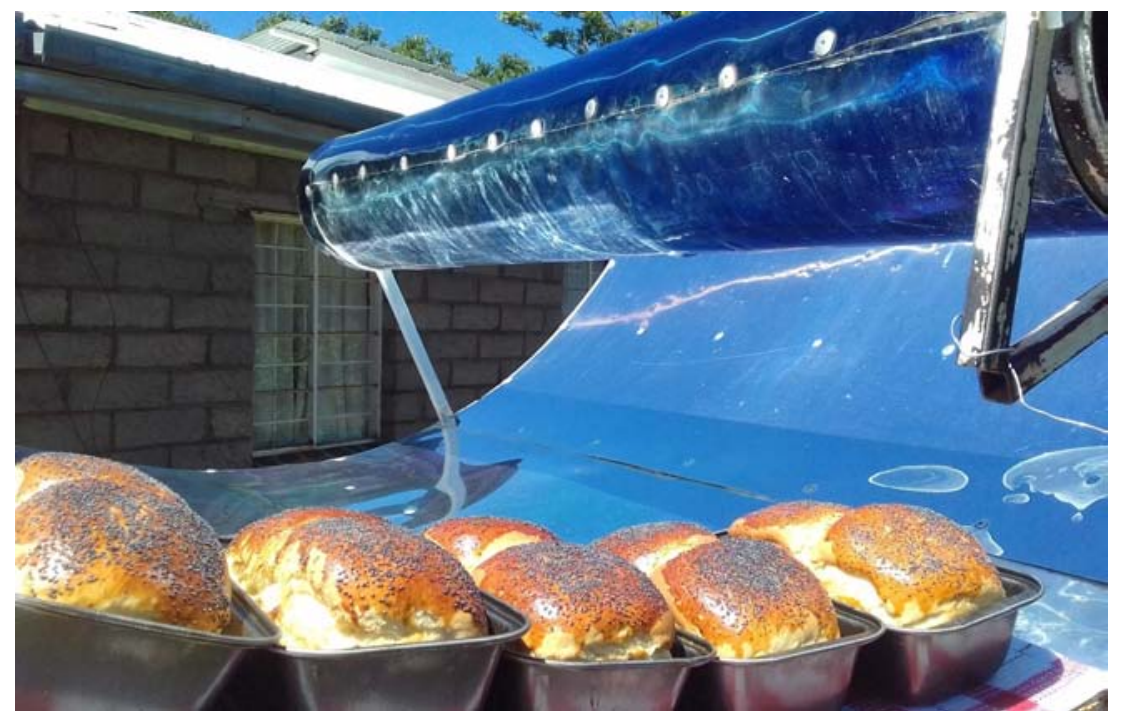

Figure 17. Buns baked in 30 minutes.

\subsection{Testing and Data Acquisition}

Baking Trial: 28/5/2017 [5]

A batch of dough for buns was mixed at about 8:30 and included:

- 8.5 cups flour (2.125 l).

- $15 \mathrm{ml}$ dry yeast.

- $5 \mathrm{ml}$ salt.

- $800 \mathrm{ml}$ water.

- $30 \mathrm{ml}$ margarine.

- $30 \mathrm{ml}$ sugar.

- 1 whole egg and the white from a second egg.

Dough was mixed using solar power from a 3KVA Victron Inverter and 760W PV system. The dough was left to rise in a warm place and punched down twice, then made out in ten small loaves to fit 5 pans and left to double in size. Before baking the top was given an egg yolk wash and sprinkled with poppy seed.

Conditions: ambient temperature was about $16^{\circ} \mathrm{C}$, sky was clear and winds were light. Instruments used are shown in Figure 18. A hole was drilled in the end of the baking tube and a temperature sensing probe was inserted. Prior to loading the oven was allowed to preheat with the end door closed. Table 2 traces the sequence of the baking trial over 40 minutes with the result displayed in Figures 20, 21. Instrumentation used is displayed in Figure 18. A radiation sensor was placed on the end and remained perpendicular to the sun (Figure 19). 
Table 2. Testing and data

\begin{tabular}{|c|c|c|c|c|}
\hline Interval Minutes & Start Time: $11: 30$ & $\mathrm{~W} / \mathrm{m}^{2}$ & Temperature & Remarks \\
\hline Empty & & 724 & $194^{\circ} \mathrm{C}$ & Tube empty and door closed. \\
\hline 0 & & 723 & $186^{\circ} \mathrm{C}$ & Oven loaded \\
\hline 5 & & 728 & $169^{\circ} \mathrm{C}$ & \\
\hline 10 & & 723 & $163^{\circ} \mathrm{C}$ & Slight cool breeze. \\
\hline 15 & & 726 & $163^{\circ} \mathrm{C}$ & \\
\hline 20 & & 725 & $166^{\circ} \mathrm{C}$ & Air still. \\
\hline 25 & & 719 & $170^{\circ} \mathrm{C}$ & \\
\hline 30 & & 725 & $173^{\circ} \mathrm{C}$ & Puffs of steam passing door. \\
\hline 35 & & 726 & $173^{\circ} \mathrm{C}$ & Aroma of baked bread evident. \\
\hline 40 & & 724 & $174^{\circ} \mathrm{C}$ & Bread removed. \\
\hline
\end{tabular}

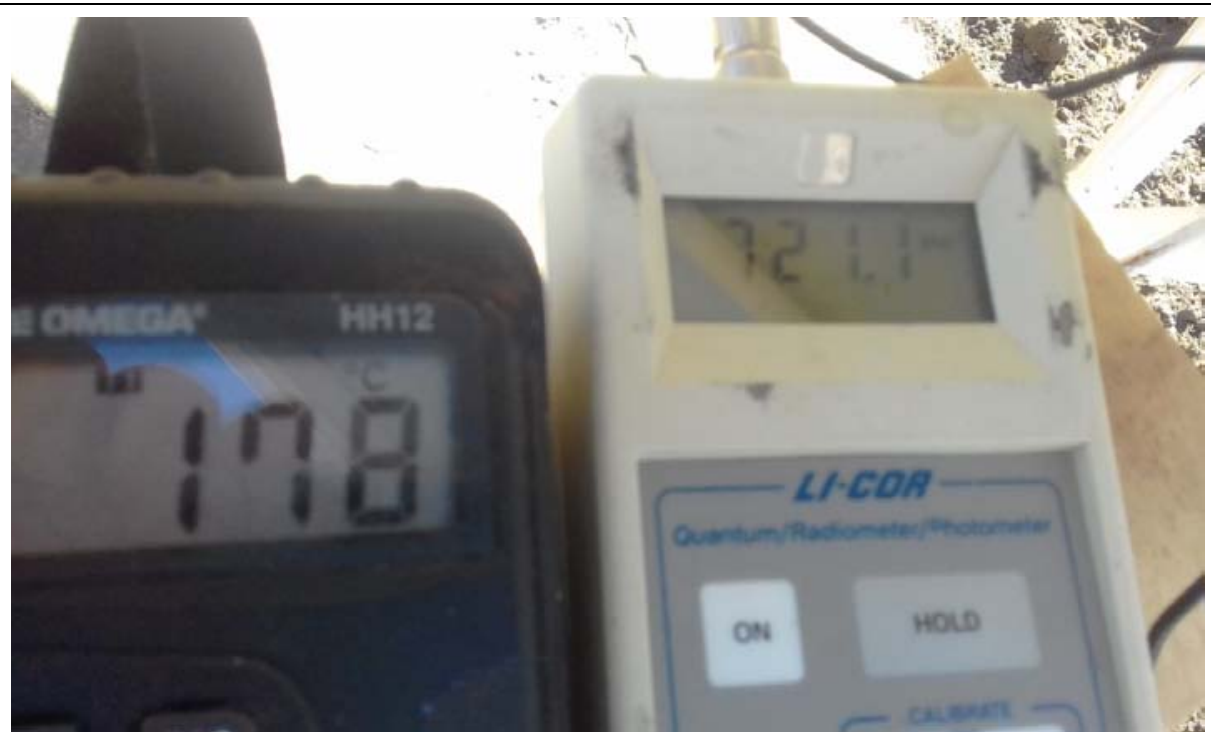

Figure 18. Instruments used for temperature and radiation measurement.

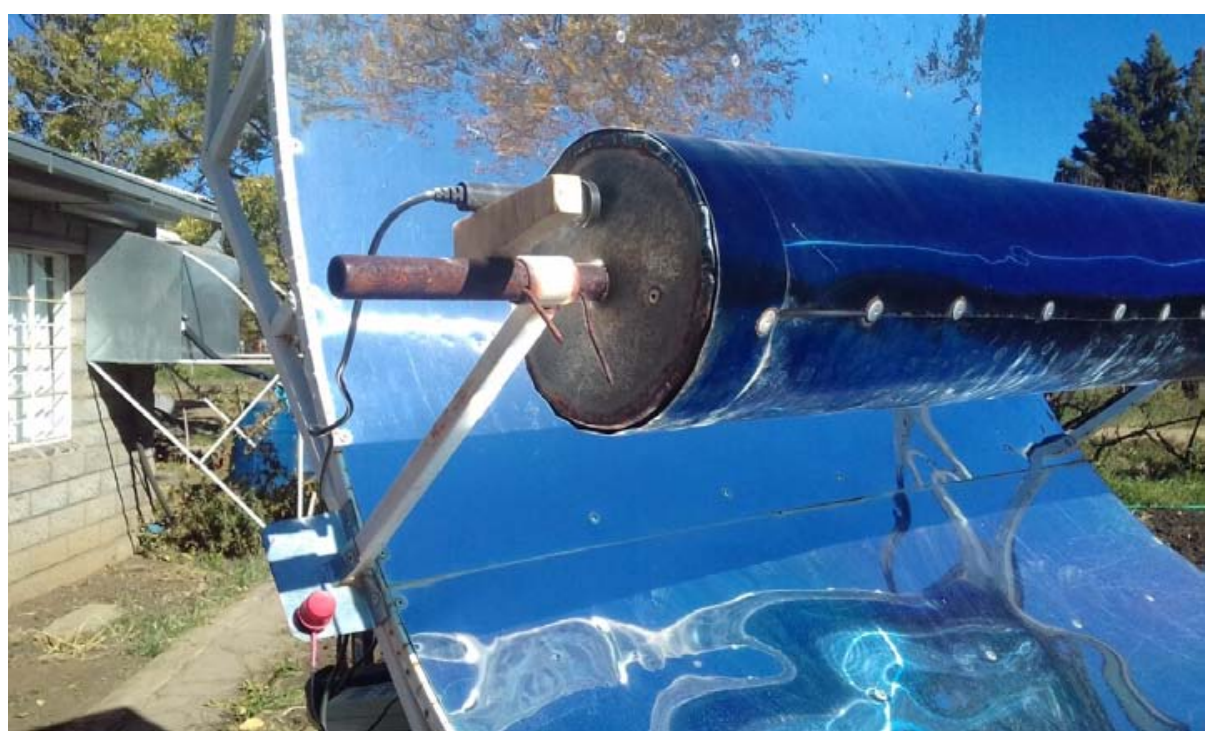

Figure 19. Temperature sense probe inserted in end and radiation sensor on focus plate. 


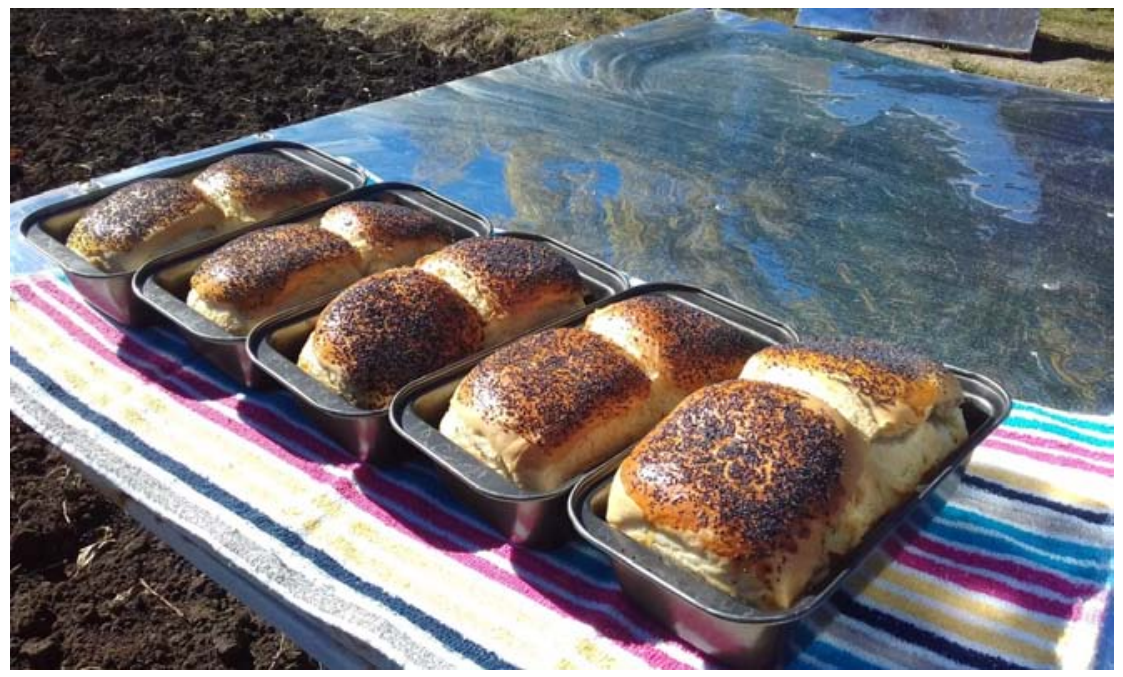

Figure 20. Loaves removed from oven.

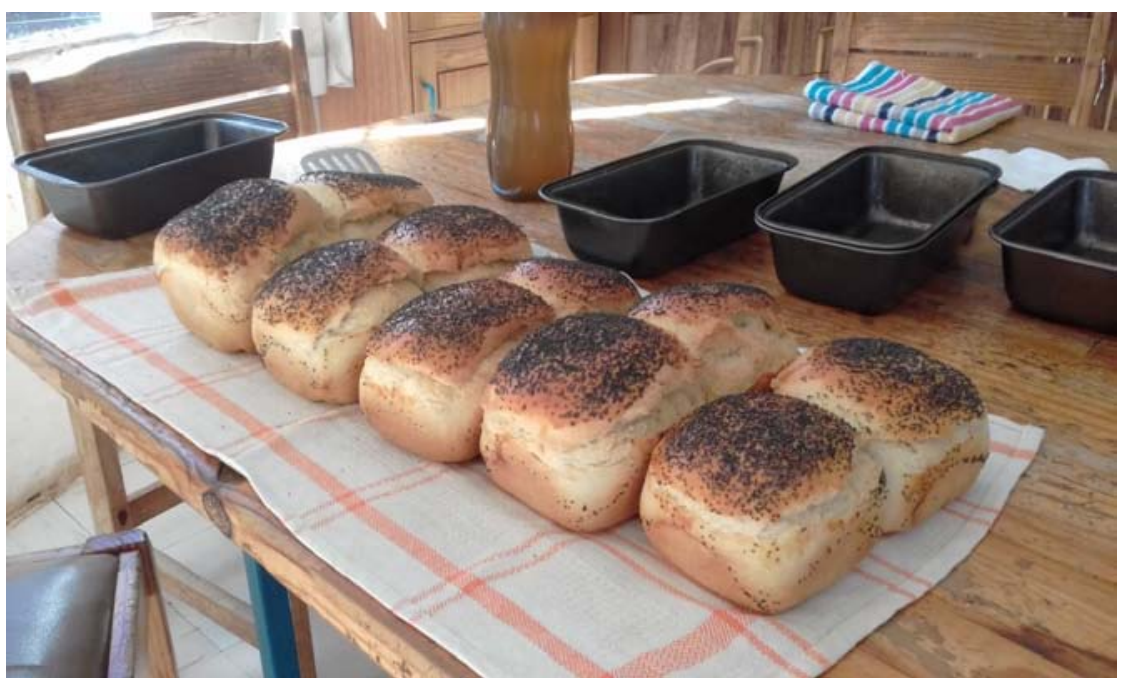

Figure 21. Loaves pop out of pans easily without sticking after a few minutes of cooling. Temperature for baking is even top and bottom. Baked loaves were weighed and totalled 1,780g altogether.

\section{Results and Discussion}

Lesotho has good solar conditions. For example, the 6 day weather forecast for the period from 1/4/2017-6/4/2017 issued by the Lesotho Meteorological weather services, predicted clear and cloudless skies, with light winds, and maximum temperatures above $30^{\circ} \mathrm{C}$ for the period (Figure 22). Lesotho receives a lot of weather like this [6].

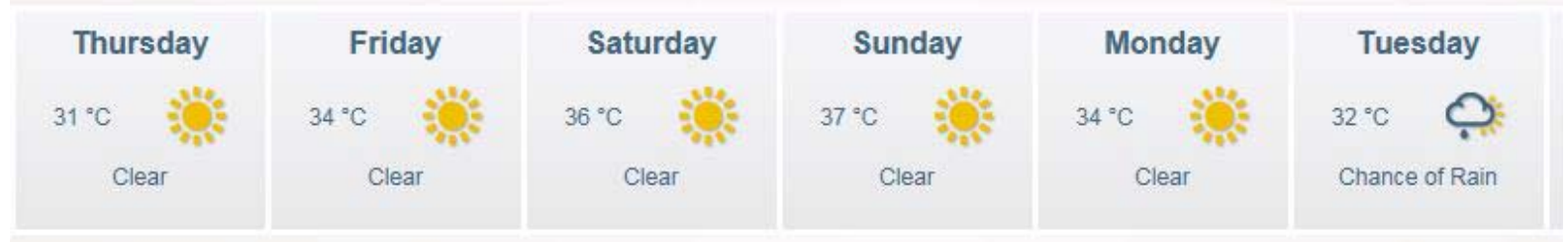

Figure 22. Typical weather forecast.

A solar oven is part of a complex pattern that includes technology, economics, food preferences, culture, infrastructure and management. In analysing the success/delay of particular technologies, the number or lack of connections may be the most important element. The advent of the SDG's in 2015 correctly captures the essence of problem solving in an interconnected world. In this case, the technology works because a broad field is encompassed and work emerged in an iterative and organic sense over a long period. It works well enough to provide a level of output with attractive economic incentives for its continuation. Furthermore, the quality of the product is high and sustains demand. It was possi- 
ble to add other elements of technology like power, a mixer, utensils and consistent procedures. When the parabola was first built in 2005, global discussion about decarbonisation of energy production was just getting started. It is more important today [7]. To what extent a system like this can scale up depends on aspiration and incentives.

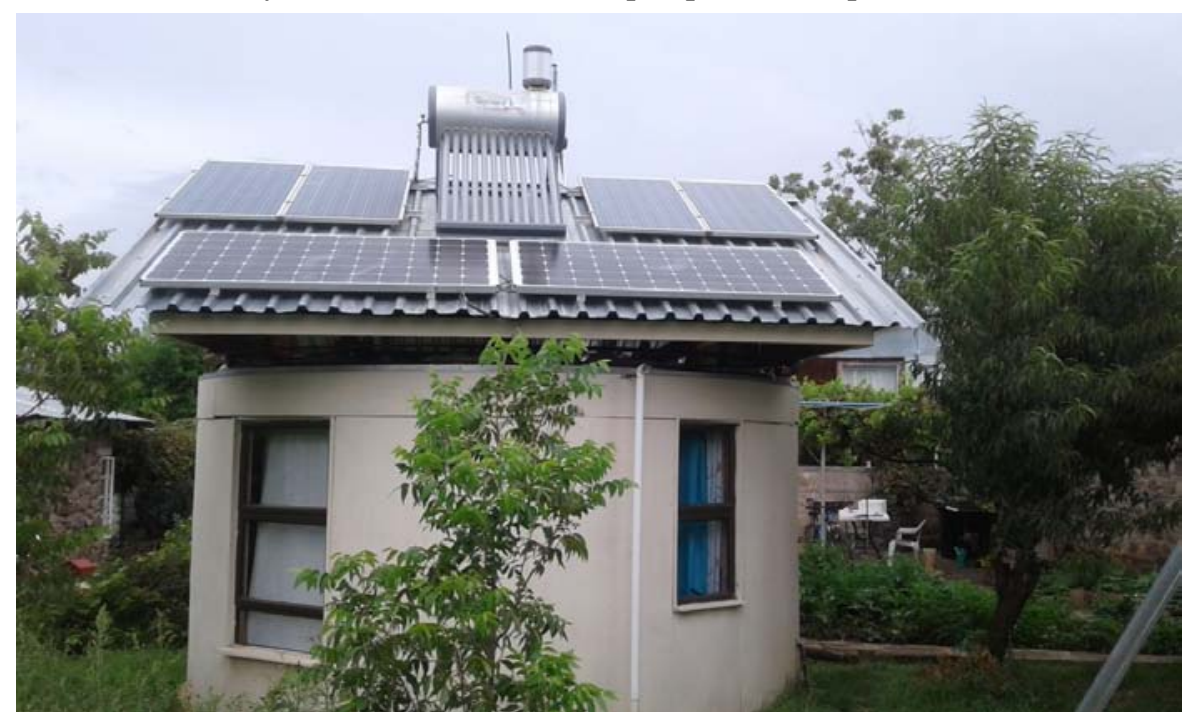

Figure 23. Rotating roof for augmented power and hot water supply adjacent to the bakery. Roof orientation depicted is straight east and provides good power soon after sun-rise for operating the dough mixer.

The parabolic baking technology is resilient and proven over a long period of time. Developers with access to basic tools and workshop equipment can replicate this oven in many regions of the world with similar solar conditions. A broad area in Southern Africa is suitable. The cost of the materials for the oven is reasonable, although bread making even on a cottage scale requires more inputs and capital investment. Around the globe humans have developed regional staple food preferences $[8,9]$. Bread as such is a relatively recent adaptation in the context of Southern Africa. Prior to the colonial period starch was provided by sorghum porridge. The cultivation of maize regionally during the last 150 years induced a shift to maize based porridge as the regional staple. Bread making was introduced by European settlers and its distribution is now widespread, even in Lesotho. Bread evolved in the Middle East and Europe along with the cultivation of wheat, milling and baking technology. The salient feature of the bread culture which pertains to the solar parabola is the high heat needed for baking. At high temperatures the characteristic crust forms on bread, where the starches are caramelized. This is what gives a French Baguette its characteristic flavour, texture and consumer preference. In this regard, the solar parabola does provide the intrinsic quality that evolved baking delivers. The author used a box cooker to bake bread for over 15 years prior to developing the parabola. While it worked, the quality and texture of the bread never matched that from conventional bakeries. This meant that a glass box cooker was not ideal. The parabola provides high quality, as is evident in Figure 20, and this is imperative for technical dissemination and commercial success.

Bread has always been a convenience food with a degree of shelf life, but is best consumed fresh. A local market has developed in Bethel for bread. Making porridge is time consuming and the food product itself is not as light and more perishable. The Bethel Bakery began by selling its entire product singly. What has evolved is that most of the bread is now collected in bulk lots by local shop keepers and retailed through extension. When the bread dough is made out for final proving, the dough is divided into separate $250 \mathrm{~g}$ balls, and stuck into the pans 4 at a time as is evident in Figure 4 . These quarters can be sold individually without cutting. Many students at local schools buy these each day. Bulk orders for special events and social activities pop up regularly. It is important to reiterate that the two parabolas support a small micro enterprise. It is not an industrial facility serving a mass market. It occupies a niche, with a capacity of 50-100 loaves per day, and operated by a single person with occasional part time help. Business models for ramping up and extending operations like this to other communities can be considered. The competitive advantage stems from energy savings and a superior product. The bun making process would mesh well with a small restaurant focusing on deli sandwiches in a busy urban market where there is a threshold of professional workers going out for lunch each day.

The question of replicating and manufacturing this device naturally arises. Some situational background is necessary. In late 2016, a high level bridge was completed over the Senqu River. This gives Bethel rapid and easy access to the highway system and logistic arteries. Prior to this Bethel was cut off from easy access by the river, and travel to town was arduous, rough and time consuming. This made Bethel a difficult location for manufacturing. With the bridge open, however, demand for the parabolic backing oven can solicit small scale manufacturing. The purpose of this paper is to 
encourage adoption and adaptation by developers, educators and small businesses. Lesotho receives an average of $36 \mathrm{MJ} / \mathrm{m}^{2} /$ day of solar radiation or 300 sunny days. Photo-voltaic devices convert up to $15 \%$ of this sunlight into usable energy, while thermal devices like solar water heaters, cookers and driers achieve 70\%-90\% efficiency. The community in which BBCDC is located remains unconnected to the national electricity grid. Solar energy technology and utilization were therefore adopted through necessity. The contribution of solar and renewable energy to operations, management and the financial viability of the community is substantial and provides for high net levels of human realization and effectiveness. A vigorous solar and renewable energy focus is included in SDG 7 and 13 (Figure 24).

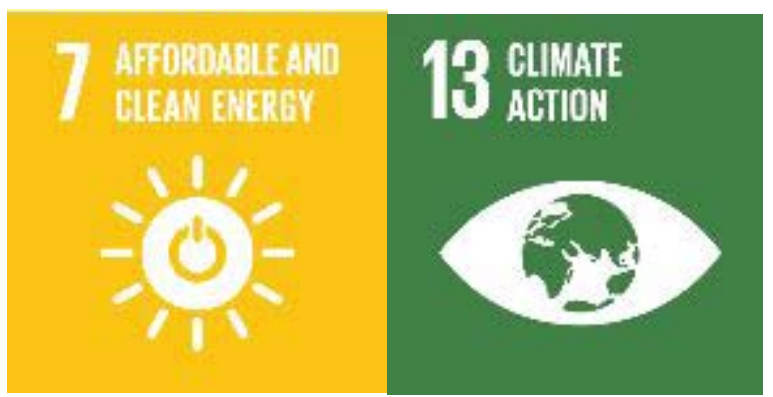

Figure 24. SDG7, 13.

\section{Acknowledgements}

Special thanks to Dr. Thomas A. Lawand, Prof Emeritus McGill University and Brace Research Institute for many productive conversations.

\section{References}

[1] Whillier, A. (1958). Unpublished Notes for Course in Solar Energy Utilization. Massachusetts Institute of Technology.

[2] Alward, R. (1982). Solar Cooker Manual. Brace Research Institute, McGill University, Technical Report T138.

[3] Serrano, P. (2020). “Solar Cookers at Complements to Traditional Restaurants.” Consolfood 2020. Conference Proceedings: Advances in Solar Thermal Food Processing. Institute of Engineering, University of Algarve, 22-23-24 Jan. 2020.

[4] 1989 ASHRAE Handbook. (1989). I-P Edition.American Society of Heating, Refrigeration and Airconditioning Engineers.Atlanta.

[5] Mbodj, Ndiaga and Hajji, Ali. (2016). "Performance Testing of a Parabolic Solar Concentrator for Solar Cooking.” Journal of Solar Energy Engineering, April, 2016.

[6] South African Development Community. Renewable Energy and Energy Efficiency: Status Report 2018. REN21. SACREEE.

[7] International Energy Agency. (2020). Global Energy Review.

[8] Bello, J. (2020). "Fighting the Energy Crisis Through Education.” Consolfood 2020. Conference Proceedings: Advances in Solar Thermal Food Processing. Institute of Engineering, University of Algarve, 22-23-24 Jan. 2020.

[9] Klapper, F., et al. (2020). "Lessons Learned from Applied Solar Cooking in Community.” Consolfood 2020. Conference Proceedings: Advances in Solar Thermal Food Processing. Institute of Engineering, University of Algarve, 22-23-24 Jan. 2020. 